\title{
Isolation impairs cognition in a social fish
}

\author{
Manuela Lombardi Brandão ${ }^{a}$, Victoria A. Braithwaite ${ }^{\mathrm{b}}$, Eliane Gonçalves-de-Freitas ${ }^{\mathrm{a}, \mathrm{c}, *}$ \\ a Departamento de Zoologia e Botânica, Instituto de Biociências, Letras e Ciências Exatas, Universidade Estadual Paulista, Cristóvão Colombo, 2265, \\ 15054-000 São José do Rio Preto, SP, Brazil \\ ${ }^{\mathrm{b}}$ Center for Brain, Behavior and Cognition, Department of Ecosystem Science and Management, The Pennsylvania State University, University Park, \\ PA 16802, United States \\ c Centro de Aquicultura da UNESP, Brazil
}

\section{A R T I C L E I N F O}

\section{Article history:}

Received 28 January 2015

Received in revised form 4 August 2015

Accepted 14 August 2015

Available online 28 August 2015

\section{Keywords:}

Cognition

Learning

Memory

Social interaction

Welfare

Social fish species

\begin{abstract}
A B S T R A C T
In variable environments, animals can learn to alter their behavior to adjust to changes. Sometimes, however, this learning ability can be impaired. For example, challenges in the social or physical environment can trigger physiological responses that compromise an individual's capacity to learn and these can prevent the animal from modifying its behavior to cope with the altered environment. One such disruption that might affect learning ability is the isolation of an individual that would normally live in a social group. To investigate the effects of isolation on cognition, we tested whether social isolation impairs learning skills in a cichlid fish, Cichlasoma paranaense. Two treatments were compared, one with isolated individuals and another with fish housed as part of a social group. Cognition was assessed in terms of the fish learning to associate a visual landmark with an accessible food reward. Fish searched for a food reward in a T-maze: a green or a yellow visual landmark signaled which chamber contained accessible food. Learning was assumed when a fish was able to find the food in nine out of ten trials. All fish, regardless of treatment, found it challenging to reach the learning criterion, but fewer isolated fish ( 3 out of 15 fish) were likely to learn the task compared to fish housed socially ( 7 out of 14 fish) (Bayesian logistic regression with $95 \%$ of chance that the two treatments differ). The results therefore suggest that social isolation for a normally social species of fish can impair learning. Furthermore, given that fish sometimes need to be isolated to treat them in a specific way, or to monitor an individual's response during a test, our results suggest that there may be some welfare implications for the way we treat and use social species of fish in empirical studies.
\end{abstract}

(c) 2015 Elsevier B.V. All rights reserved.

\section{Introduction}

Animals perceive and interpret environmental information through cognitive processes, and use learning and memory to help them modify their behavior (Braithwaite, 2006). To gain a better understanding of how such cognitive processes function, we can compare how different animals learn and remember information (Bshary et al., 2002). In the last two decades, there has been a considerable growth in knowledge about animal cognition, particularly in birds and mammals (Dukas, 2004), however, fewer studies have focused on groups such as fish (Huntingford, 2003;

\footnotetext{
* Corresponding author at: Departamento de Zoologia e Botânica, Instituto de Biociências, Letras e Ciências Exatas, Universidade Estadual Paulista, Cristóvão Colombo, 2265, 15054-000 São José do Rio Preto, SP, Brazil.

E-mail addresses: manulbrandao@gmail.com (M.L. Brandão), v.braithwaite@psu.edu (V.A. Braithwaite), elianeg@ibilce.unesp.br (E. Gonçalves-de-Freitas).
}

Braithwaite, 2006). Yet, it is becoming increasingly recognized that many species of fish are capable of developing sophisticated behaviors that require the integration of different kinds of information and that are presumably underpinned by complex cognitive processes (Braithwaite and Salvanes, 2008).

From an evolutionary perspective, the brain structure of vertebrates and many of the cognitive processes that these systems support appear to be relatively conserved (Broglio et al., 2005; Portavella et al., 2004; Brown, 2014). Fish, for example, have been shown to have several homologous brain regions found in other vertebrates (Nieuwenhuys and Meek, 1990; Salas et al., 2003). Huntingford (2003) describes how several learning skills in fish are comparable to those seen in mammals; for example, fish exhibit social learning, they develop migratory strategies and they can learn to avoid places that predators frequent (Brown and Laland, 2003). In addition to this, many fish species are capable of learning complex spatial relationships and can use landmarks, geometry and form mental maps (Rodríguez et al., 1994; Odling-Smee and Braithwaite, 2003a). These specialized learning skills in fish depend 
upon a brain structure in the telencephalon known as the dorsal lateral area (DL) that has been proposed to be homologous to the hippocampus of birds and mammals (Broglio et al., 2003). Fish use their learning skills to provide a degree of behavioral flexibility that aids survival and development, and their cognitive processes are supported by changes in neural plasticity that promote adaptive responses when they are challenged by new situations (Kandel, 2001; Ebbesson and Braithwaite, 2012).

Two factors that play a significant role in shaping an animal's nervous system are environmental and social interactions (Shumway, 2010). An environment that is rich in stimuli is more complex and promotes neural growth and learning (Salvanes et al., 2013). With respect to the social environment, the social brain hypothesis suggests that, the more complex the social interactions between individuals, the greater the development of the nervous system underpinning the behavior of those animals (Byrne and Whiten, 1988; Dunbar, 1998). Moreover, social observation, and learning that arise from these observations, provides an individual the ability to adjust its behavior rather than having to spend time and energy learning by trial and error (Manassa et al., 2013). Thus, social interactions provide neural stimulation that increases the number of synaptic connections and neurogenesis (Coss and Globus, 1978; Young et al., 1999; Dunlap et al., 2006) and this promotes neural plasticity and learning. Social individuals deprived of interactions, even for a short-term period, can exhibit a reduction in brain cell proliferation, which can lead to impaired learning and memory processes (Han et al., 2011).

Fish are commonly used as model organisms in biomedical trials, or to test evolutionary biology hypotheses (e.g. Panula et al., 2010; Howe et al., 2013; Bell and Aguirre, 2013). Teleost fish exhibit the greatest neurogenesis seen in any adult vertebrate (Zupanc, 2008), making them an excellent organism in which to study the relationship between social organization, environmental challenges and their effects on neural systems (Bshary et al., 2002). Many of the fish species used in experiments normally live in social groups, but certain kinds of experiment require that the fish be kept in isolation (Gómez-Laplaza and Morgan, 2000). Social isolation in teleost fish has been shown to alter aggressive behavior (Gonçalves-de-Freitas and Mariguela, 2006), locomotor and feeding activity (Gómez-Laplaza and Morgan, 2003), and the neuroendocrine system (Hannes and Franck, 1983). The aim of the current study was to extend these observations and to address whether isolation in a social species of fish also impairs cognitive performance.

Cichlid fishes are social animals that live in several kinds of habitat and show a range of complex social behaviors (Barlow, 2000; Shumway, 2010). However, due to their aggressive nature, many species of cichlids that are maintained as ornamental fish (Barlow, 2000) and those used in research (Bshary et al., 2002; Shumway, 2010; Seehausen, 2006), are frequently kept in isolation (e.g. Gonçalves-de-Freitas and Mariguela, 2006). We used the social, neotropical cichlid fish Cichlasoma paranaense to test whether social isolation affects learning skills. While there are only a few studies with this species, none of them have addressed social interactions, however, $C$. paranaense display high levels of aggression to other cichlids, which is a common response across the Cichlasoma genus (e.g. Alonso et al., 2011). We therefore quantified the learning performance of fish kept in social isolation with fish that were group housed.

\section{Methods}

\subsection{Subjects and rearing conditions}

Juvenile $C$. paranaense of unidentified sex (members of this species are sexually monomorphic) were caught in natural ponds at
Table 1

An ethogram of the main aggressive interactions seen in C. paranaense.

\begin{tabular}{|c|c|}
\hline Observed behavior & Description of behavior \\
\hline Lateral threat & $\begin{array}{l}\text { A fish approaches quickly toward its opponent that } \\
\text { swims away }\end{array}$ \\
\hline Chasing and fleeing & $\begin{array}{l}\text { A fish swims in the direction of its opponent, causing } \\
\text { the opponent to flee }\end{array}$ \\
\hline Lateral fighting & $\begin{array}{l}\text { A fish intensively undulates its body against the } \\
\text { opponent sometimes touching and displacing the } \\
\text { opponent. }\end{array}$ \\
\hline Biting & A fish approaches its opponent and bites its body \\
\hline Pushing & $\begin{array}{l}\text { A fish with its open mouth nips the lateral flank of its } \\
\text { opponent, sometimes displacing the opponent }\end{array}$ \\
\hline Pulling fins & $\begin{array}{l}\text { A fish bites its opponent's fin, moving the opponent } \\
\text { away by pulling the fins }\end{array}$ \\
\hline Mouth fighting & $\begin{array}{l}\text { Two fish approach one another and simultaneously } \\
\text { bite their jaws. They may swim in a circle while keeps } \\
\text { their mouth attached }\end{array}$ \\
\hline
\end{tabular}

a farm in Icém city, São Paulo State $\left(20^{\circ} 20^{\prime} 31^{\prime \prime}\right.$ S and $\left.49^{\circ} 11^{\prime} 42^{\prime \prime} \mathrm{O}\right)$. They were then raised in a common outdoor tank at the UNESP, São José do Rio Preto, SP, Brazil. Before the beginning of the study, fish were acclimated to laboratory conditions in $500 \mathrm{~L}$ indoor tanks (ca one fish per $15 \mathrm{~L} ; 27^{\circ} \mathrm{C}$ and $12 \mathrm{~h}$ light/dark cycles) for 15 days. Biological filters and constant aeration ensured water quality. Fish were fed to satiation with a commercial ration for tropical fish, Pirá ${ }^{\circledR} 28 \%$ protein, twice a day.

\subsection{Experimental design}

We compared spatial learning ability in two groups of fish; one consisted of socially isolated individuals $(n=15)$ and the other was made up of the most dominant individual sampled from different social groups of four fish $(n=14)$. We chose to compare isolated fish with the most dominant fish in the group-housed treatment because the dominant individuals could be readily identified in their group, and it allowed us to compare individuals of the same rank across each of the group-housed treatment tanks. In addition, other studies with cichlid fish have found that when a fish is placed in isolation it becomes dominant in its new social environment (Figler and Einhorn, 1983; Fernald, 2009).

Before the learning tests, the fish were housed for 10 days in aquaria $(30 \times 30 \times 40 \mathrm{~cm})$ for habituation (isolated fish) and hierarchy establishment (group-housed fish). The group-housed fish were filmed for $10 \mathrm{~min}$ every two days to monitor their interactions using an ethogram developed for $C$. paranaense (see Table 1). A period of 10 days was used as this has previously been shown to be sufficient to reduce the influence of prior social experience in fish (e.g. Dunlap et al., 2006; Barreto et al., 2006).

Social groups were formed by putting four individuals of heterogeneous size (between 6.0 and $10.0 \mathrm{~cm}$ standard length) together. Each group's hierarchy was determined by calculating a Dominance Index (DI = individual aggressive acts/group aggressive acts), with the dominant fish (alpha) scoring the closest to $1.0 \mathrm{DI}$ (e.g. Oliveira and Almada, 1996; Gonçalves-de-Freitas et al., 2008; Barreto et al., 2011). Before being put into aquaria on the first day of experimentation, the social group and the isolated individual were anesthetized with tricaine methanesulfonate, MS222 (Sigma-Aldrich, China) (20 mg/L) and tagged below their dorsal and opercular scales using Visible Implant Elastomer tags (Northwest Marine Technology, Inc., USA) with different colors to allow individual identification, fish in both treatments were treated similarly in terms of handling and manipulation. The MS222 was chosen because it is an anesthetic that does not require alcohol for its dilution (which can affect neurological processes), and because it has previously been used in other studies successfully measuring fish learning (e.g. Portavella et al., 2004; Salvanes et al., 2013). 

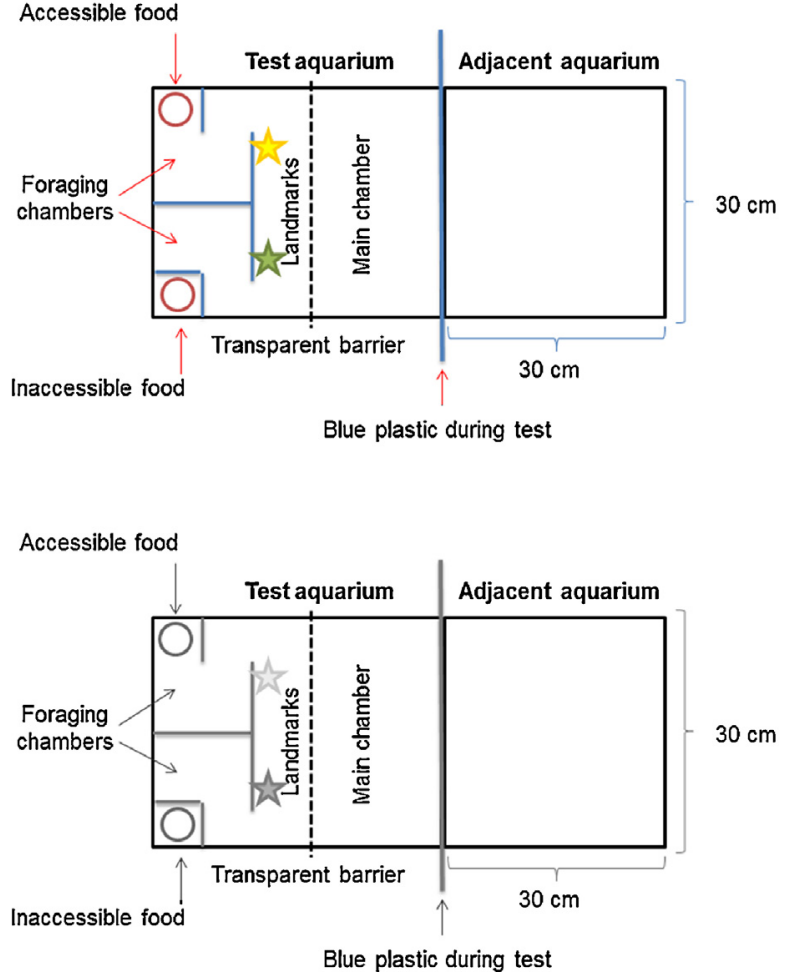

Fig. 1. Schematic view of test aquarium seen from above. There were two possible routes that fish could take to find food (guided by a green or yellow star shaped symbol). The rest of the tank area, the main chamber, is where fish remained when the test was not being run. The adjacent aquarium, on the right, was where the three remaining group members were maintained for so that the group-housed test fish had visual contact with the rest of their social group. This tank was empty for individuals in the isolated treatment. (For interpretation of the references to color in this figure legend, the reader is referred to the web version of the article.)

\subsection{Spatial learning}

After allowing the fish to settle for 10 days, isolated and group-housed fish were transferred to individual test aquaria $(40 \times 30 \times 40 \mathrm{~cm} ; 48 \mathrm{~L})$ where they remained until the end of experiment. The aquaria's side and back walls were covered with blue plastic to avoid visual contact between replicate tanks. Blue was used because it has been shown to reduce stress in another species of cichlid fish, the Nile tilapia, Oreochromis niloticus (Volpato and Barreto, 2001; Maia and Volpato, 2013). The front wall was left uncovered and this was positioned so that it faced a separate aquarium where the three remaining group members were housed so that they remained in visual contact with the dominant fish. For the isolated individual, the front wall faced an empty aquarium. The test aquarium was divided into three chambers: two for foraging and one where the fish spent the rest of its time (see Fig. 1).

When the trials were not being run, the foraging chambers were separated from the main chamber by an opaque, plastic partition that prevented fish accessing that part of the tank. At the start of a trial, this opaque plastic partition was removed and another opaque barrier was placed between the test aquarium and the adjacent aquarium, so that all test fish were visually and physically isolated at the time of testing. A transparent barrier was then placed between the foraging chambers and the main chamber to allow the foraging chambers to be baited while the test fish was confined in the main chamber (see Fig. 1). Two cups with food (fresh shrimp) were placed in each foraging chamber but in only one of these was the food accessible (inaccessible food was placed into a cup with a perforated plastic cover which allowed the fish to smell the food, but it could not be consumed). After two minutes, a video camera over the top of the tank was switched on and the transparent barrier was removed, allowing test fish access to the foraging chambers. The latency before fish began swimming after the transparent barrier was removed was noted.

Visual landmarks in the form of green or yellow star shaped symbols were placed at the entrance of each foraging chamber. Each fish was given a consistent side and color to learn to identify the location of the accessible food, and the other color and side had inaccessible food (Fig. 1). Several species of fish have been shown to use such visual and spatial cues to help them learn foraging tasks (Odling-Smee and Braithwaite, 2003a), and cichlids are known to perceive and differentiate several different colors in their environment (Hofmann et al., 2009; Sabbah et al., 2010; Brown, 2014). The side on which food was made accessible and the color of the rewarded chamber landmark were counterbalanced across both the group-housed and isolated treatment groups.

Individuals were tested for $15 \mathrm{~min}$, twice a day between 8:00-10:00 h and 14:00-16:00 h, for 15 days. A learning criterion of nine correct choices (defined as entering the correct, accessible food chamber first and consuming the food) out of 10 trials was used (e.g. Odling-Smee and Braithwaite, 2003b). Fish were trained until they reach the criterion or until they had completed 30 trials without achieving the learning criterion and so categorized as nonlearners. On completion of the experiment, the fish were killed with an overdose of benzocaine and they were then measured and dissected to permit sex identification. The isolated group consisted of seven males and eight females, and the group-housed fish consisted of two males and 12 females. The standard length was controlled for both treatments and revealed a mean standard length ( \pm SE) of $8.91 \pm 0.21 \mathrm{~cm}$, in group housed fish, and $9.39 \pm 0.15 \mathrm{~cm}$, for isolated fish.

\subsection{Statistical analyses}

Bayesian models have been considered as a good model to analyze a range of behavioral parameters and can be used to generate probabilities that explain behavioral patterns (McNamara et al., 2006). Here, we fitted Bayesian logistic regression models to estimate each subject's ability to learn the task, and the number of trials needed for each fish to reach the learning criterion. As there were unequal numbers of males and females in the treatments groups, we compared the possible effect of sex on whether males and females differed in their ability to reach the learning criterion. Both analyses used the following model:

$W i \sim \operatorname{Binomial}(\lambda(i), \lambda(i))$

$\lambda(i) \sim \operatorname{Beta}(0.5,0.5)$

where the subscript " $i$ " represents the "ith" observation. The first term (1) specifies the error with an independent Binomial distribution, and the parameter " $\lambda$ " from the second term (2) represents the means from both variables using an uninformative prior.

The motivation of the two groups to perform the task was compared in a similar analysis by comparing the latency for the fish to resume swimming after the transparent barrier was removed at the start of a trial. This was compared to determine how quickly fish recovered from the movement of the water associated with the barrier removal. We also compared the number of times an individual entered a foraging chamber to investigate whether the fish were exploring the T-maze and sampling the two arms and feeders, or whether the fish spent most of their time stationary. The foraging activity of the two groups was also compared by investigating the latency for the fish to totally consume the food reward. The last three analyses were compared using the following model:

$Y i \sim \operatorname{Normal}(m u(i), \quad$ tau $)$ 
(a)

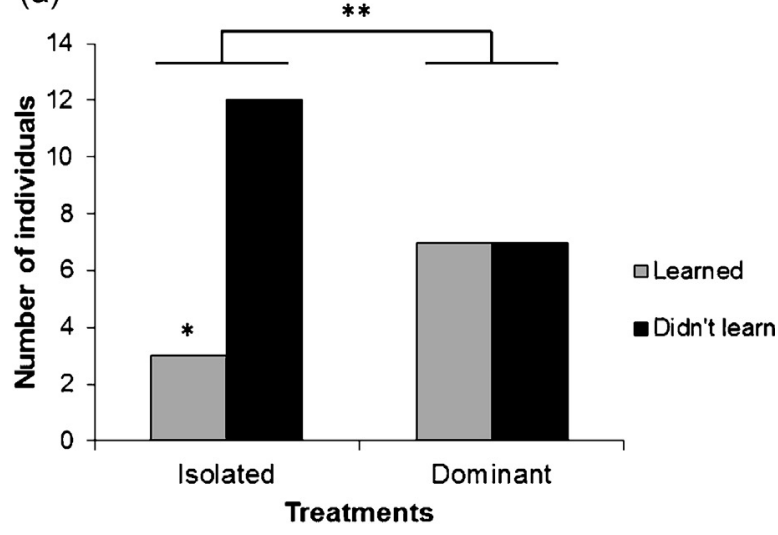

(b)

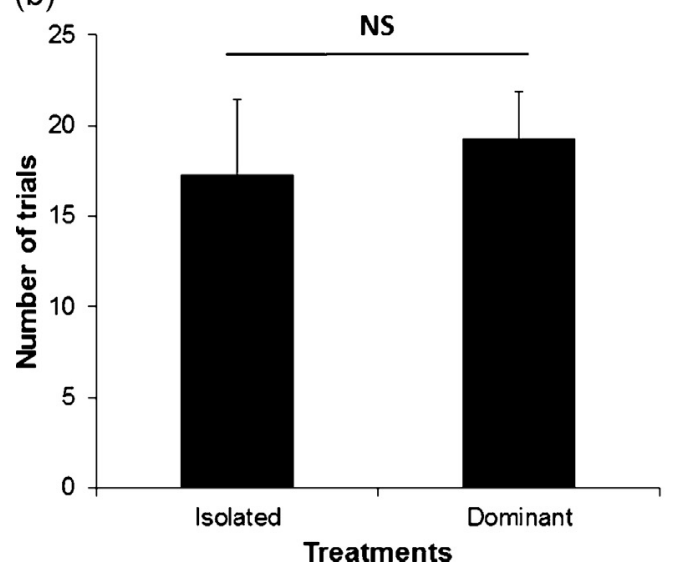

Fig. 2. (a) Number of individuals that achieved the $9 / 10$ learning criterion in each treatment (Bayesian logistic regression); (b) mean \pm SE of the number of trials taken for fish to learn the task (Bayesian logistic regression). * indicates $99 \%$ probability that fish differ between those individuals who learned and those that did not learn the task in social isolation treatment. ${ }^{* *}$ indicates strong probability (95\%) that the two treatments differed from each other.

$m u(i)=b[Y(i)]$

where the subscript $i$ represents the $i$ th observation. The first term (3) specifies the error with an independent normal distribution, and the second term (4) determines the linear model with the parameter " $b$ " specifying the average for each category " $Y$ ".

We considered $95 \%$ as a significant probability to explain the differences between and within treatments.

\subsection{Ethical approval}

This study was conducted according to the ethical guidelines of the Conselho Nacional de Controle de Experimentação Animal (Brazilian National Council for the Control of Animal Experiments - CONCEA) and was approved by the Ethical Committee of Animal Experimentation of the São Paulo State University (UNESP, SP, Brazil, permit 063/2012).

\section{Results}

\subsection{Ability to reach the learning criterion}

Fish from the isolated and group-housed treatments differed with a probability of $95 \%$ in terms whether they learned the task, with isolated fish being less able to learn than the group-housed fish (Fig. 2a). There was a $50 \%$ probability that individuals from the (a)

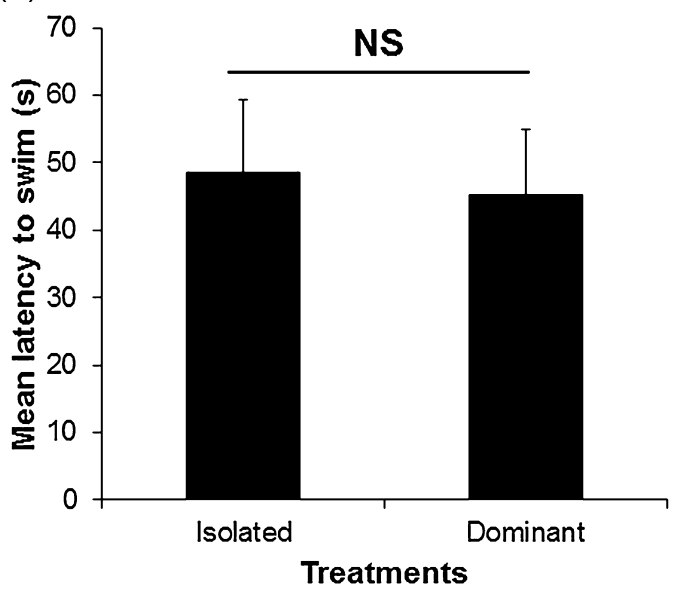

(b)

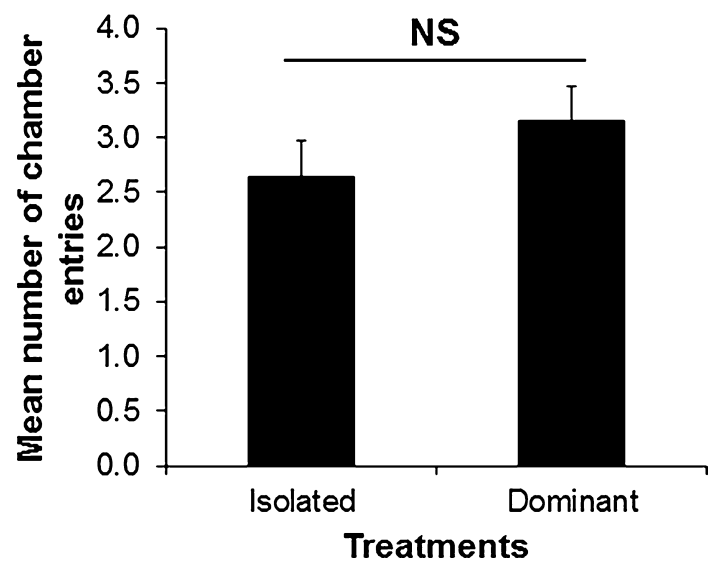

Fig. 3. Mean \pm SE: (a) probability of $59 \%$ that the latency before the fish started to swim in each trial is different between the treatments; (b) probability of $50 \%$ that the number of times the fish entered one of the foraging chambers in each trial is different between treatments.

group-housed treatment did or did not learn to solve the maze ( 7 fish reached the learning criterion while 7 fish did not, Fig. 2a). The isolated treatment fish, however, had a 99\% probability of not being able to learn the task, with only 3 out of 15 fish achieving the learning criterion (Fig. 2a). Comparing the fish that did reach the learning criterion, there was no difference in how quickly they took to learn the task, with only a $28 \%$ chance of a difference being found (Fig. 2b).

\subsection{Motivation profile}

The latency of fish to start swimming again once the barrier was removed at the start of the test did not differ between fish from the isolated or group-housed treatments; there was a 59\% probability that the groups differed from each other (Fig. 3a). Similarly there was no difference in the number of times fish from the isolated or group housed treatments entered a foraging chamber $(50 \%$ probability that the fish differed, Fig. 3b).

\subsection{Feeding activity}

There was a difference between the treatments in terms of the latency to feed in the trials; there was a 93\% chance that the group housed fish consumed the food before fish from the isolated treatment (Fig. 4). 


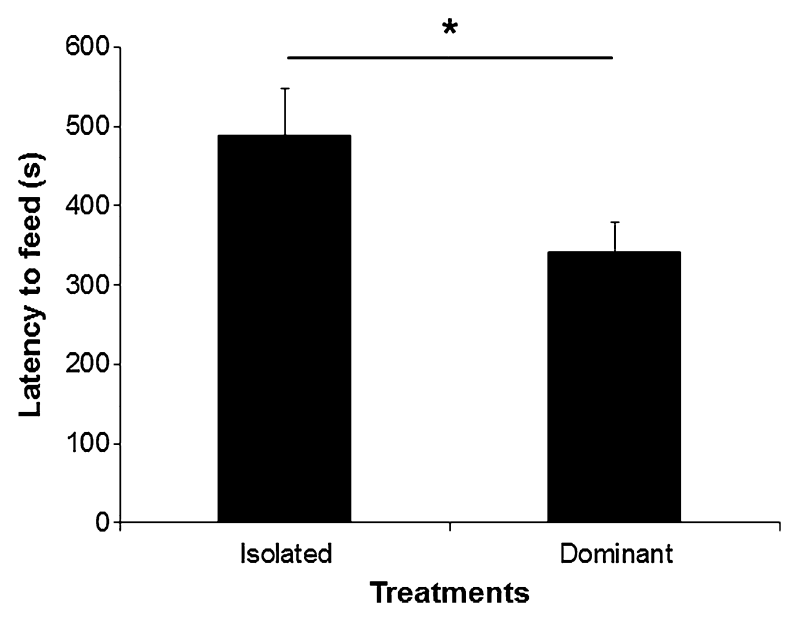

Fig. 4. Mean $\pm S E$ of the latency to fish start to eat in each trial. * indicates $93 \%$ probability that the treatments are different.

\subsection{Sex effects}

In the isolated fish treatment, one male of seven and two females of eight fish learned the task. In the group-housed treatment, seven females fish learned the task and five did not, but neither of two males in this treatment learned the task. When compared in the logistic regression model, there was a sex effect with a $95 \%$ chance that more females than males learned the task, however, given the low numbers of male and female fish contributing to this analysis caution should be applied to interpreting this result. There were no differences in the number of times males and females entered the foraging chamber (with $50 \%$ chance of the treatment groups differing).

\section{Discussion}

Cichlid fish that experienced ten days of isolation before being trained in a spatial task were less likely to learn the correct route; only three out of 15 fish reached the learning criterion in contrast to half the fish from the group-housed treatment (seven). To learn the location of the accessible food reward, the fish had to associate a visual landmark and, or, the position (left or right) of one of two food reward chambers. The results suggest that, regardless of treatment, all fish found it difficult to achieve the learning criterion, but those that experienced social isolation had the most difficulty learning to solve the task. Yet keeping fish in isolation is not uncommon in captive settings, particularly in research laboratory situations where fish are used as experimental subjects (Gómez-Laplaza and Morgan, 2000; Galhardo and Oliveira, 2014), however if doing this disrupts their ability to learn, we should consider whether this affects not just the behavioral responses of the fish, but also their welfare (Huntingford et al., 2006).

Cichlids are considered both behaviorally and physiologically flexible in that they can adjust their behavior and adapt to cope with changes in their social environment (Huffman et al., 2012). A comparison of motivation across the two groups tested here revealed no differences in the latency to begin swimming at the start of a trial, or the number of times they entered the foraging chambers, and the rate at which fish that did learn the task was similar for both treatment groups. Together, these results suggest that there were no overall differences in the motivation, activity of the fish or general learning strategy. Of these findings, it is important to note that compromised motivation in the socially isolated fish does not seem to explain their poor learning performance.

In situations where there are high levels of environmental variation, or when an immediate action to some kind of challenge is required, an animal's nervous system must respond quickly and learning processes can help refine how the animal behaves. Indeed, fish that live in enriched environments, with stimuli richness exhibit a greater level of neural activity and a superior ability to learn (von Krogh et al., 2010; Salvanes et al., 2013). Although stimulation provided by the physical environment is important, social interactions can also exert a considerable influence over neural plasticity (Dunbar and Shultz, 2007). Bshary (2011) proposes that social interactions have an important role in selecting for individual cognitive skills. In our study, a lack of social stimulation appears to have impaired the ability of the fish to associate food with a particular landmark and position. We also found that fish from the isolated treatment were slower to consume the food reward. When animals are anxious they can show an increased wariness when performing specific behaviors such as foraging (Øverli et al., 2002; Chaby et al., 2015). The effects of the isolation may therefore have led to increased levels of anxiety that could explain this effect. A lack of social stimulation may therefore negatively affect the overall wellbeing and welfare of fish that are used to existing in social groups (Huntingford et al., 2006).

Territorial fish, like $C$. paranaense, need to recognize the boundaries of their territory, and have to track the position of shelter so that they can quickly seek refuge when threatened (Braithwaite, 2006). Thus, we expected that the fish would be able to use spatial cues to learn the position of the food reward. However, $80 \%$ of the isolated individuals were unable to learn the association between the spatial cues and the accessible food reward. It seems likely that the stress induced by social isolation may have contributed to the learning deficit seen in the isolated treatment group. A study by Øverli et al. (2002) found that only six days of social isolation were sufficient to induce chronic stress in rainbow trout, Oncorhynchus mykiss. It has also been shown that social isolation for only $24 \mathrm{~h}$ in the cichlid fish Archocentrus nigrofasciatus, results in an increase of cortisol levels (Earley et al., 2006). Social stressors have been found to directly reduce cell proliferation in the telencephalon of rainbow trout (Sørensen et al., 2011) and they are associated with the loss of neurons that support learning and memory processes (Zhang et al., 2006). Recently, Galhardo and Oliveira (2014) showed that cortisol variation is influenced by the previous social status of fish, in Oreochromis mossambicus. Here we did not know the previous status of the juvenile fish and, although we did not directly assess stress physiology, it seems likely that the ten days of social isolation challenged the $C$. paranaense in such a way that it impaired their spatial learning.

Alternative behaviors that could be compromised in the isolated fish, such as swimming (Gómez-Laplaza and Morgan, 2003) were also quantified. Isolated fish have previously been found to exhibit reduced swimming activity after a 10 days period in isolation (Gómez-Laplaza and Morgan, 1991). A decrease in activity could be adaptive for individuals that find themselves in social isolation because being solitary may make an individual more prone to danger such as predation, and decreased activity would lower an individuals' detectability (Gómez-Laplaza and Morgan, 1991, 2003). To confirm that impaired performance in the learning task was altered because of an effect on learning, and not some alternative change in motivation induced by the reduction in social stimulation, we compared the exploratory profiles of fish in both the isolated and group-housed treatments. We found no differences in latency to start exploring or in the number of entries into the foraging chambers. Thus, isolated and group-housed fish had similar levels of motivation to find the food (reward), suggesting that the differences between treatments likely represent differences in learning.

Although the fish are sexually monomorphic, we were able to determine how many males and females there were at the end of the experiment after the fish were euthanized. For neotropical 
cichlids, it is common to observe biparental care of offspring, with both males and females displaying aggressive behaviors and defending their territory (Holder et al., 1991; Teresa and Gonçalvesde-Freitas, 2011; Ramallo et al., 2014) so both sexes are motivated to fight and show aggression. In this study, we chose to work with sexually immature individuals to try to reduce potential effects of reproductive behavior or sex hormones on the behaviors we wished to measure. Gender differences in aggressive behavior were found for adult Amatitlania nigrofasciata (Arnott and Elwood, 2009), but a recent study by Pinho-Neto et al. (2014), with the Nile tilapia ( $O$. niloticus) found no difference in aggressiveness between juveniles of both sexes, nor a sex difference in the probability of winning a fight. In the current study, it is difficult to conclude whether or not there are sex differences in the learning ability of the fish. While more females appear to have learned the task, this is based on a very small sample size so the reliability of that result is unclear.

The results from our study indicate that a lack of social stimulation can impair learning skills and, consequently, social isolation may influence the behavior of fish used in experiments. Combining these observations with previous research that shows how isolation of naturally group living fishes triggers a stress response, it seems likely that social isolation has a negative effect on the welfare of the isolated individuals (Øverli et al., 2002). The act of isolating normally group living fish may interfere with how the fish judge situations and adjust their behavior which could lead to inappropriate behavioral responses (von Krogh et al., 2010). Our results are not just restricted to fish kept in isolation for research, but they could also have implications for ornamental fish also kept isolated to avoid fights (Gonçalves-de-Freitas and Mariguela, 2006). We suggest that further research is now needed to determine how best to house different species of fish, and how to provide them with sufficient social stimulation while limiting the opportunities for escalation to aggressive interactions.

\section{Conflict of interest}

The authors declare no conflicts of interest.

\section{Acknowledgements}

We thank to MSc. Roselene S. Costa Ferreira, Gisele Colognesi and Ana Paula Montedor for technical assistance during data collection and Eurico Mesquita Noleto Filho for all the statistical support. This research was funded by Fundação de Amparo à Pesquisa do Estado de São Paulo (proc. 2012/10903-5) and Conselho Nacional de Desenvolvimento Científico e Tecnológico (proc. 130295/2012-4).

\section{References}

Alonso, F., Cánepa, M., Moreira, R.G., Pandolfi, M., 2011. Social and reproductive physiology and behavior of the neotropical cichlid fish Cichlasoma dimerus under laboratory conditions. Neotrop. Ichthyol. 9, 559-570.

Arnott, G., Elwood, R.W., 2009. Gender differences in aggressive behaviour in convict cichlids. Anim. Behav. 78, 1221-1227.

Barlow, G.W., 2000. The Cichlid Fishes: Nature's Grand Experiment in Evolution. Basic Books, USA, pp. 335.

Barreto, R.E., Volpato, G.L., Pottinger, T.G., 2006. The effect of elevated blood cortisol levels on the extinction of a conditioned stress response in rainbow trout. Horm. Behav. 50, 484-488.

Barreto, R.E., Arantes Carvalho, G.G., Volpato, G.L., 2011. The aggressive behavior of Nile tilapia introduced into novel environments with variation in enrichment. Zoology 114, 53-57.

Bell, M.A., Aguirre, W.E., 2013. Contemporary evolution, allelic recycling, and adaptive radiation of the threespine stickleback. Evol. Ecol. Res. 15, 377-411.

Braithwaite, V.A., 2006. Cognitive ability in fish. Fish Physiol. 24, 1-37.

Braithwaite, V.A., Salvanes, A.G.V., 2008. Cognition: learning and memory. In: Magnhagen, C., Braithwaite, V.A., Forsgren, E., Kapoor, B.G. (Eds.), Fish Behaviour. Science Publisher, Inc., USA, pp. 33-60.
Broglio, C., Rodríguez, F., Salas, C., 2003. Spatial cognition and its neural basis in teleost fishes. Fish Fish. 4, 245-255.

Broglio, C., Gomez, A., Duran, E., Ocana, F.M., Jimenez-Moya, F., Rodríguez, F., Salas, C., 2005. Hallmarks of a common forebrain vertebrate plan: specialized pallial areas for spatial, temporal and emotional memory in actinopterygian fish. Brain Res. Bull. 66, 277-281.

Brown, C., Laland, K.N., 2003. Social learning in fishes: a review. Fish Fish. 4 280-288.

Brown, C., 2014. Fish intelligence, sentience and ethics. Anim. Cogn. 18, 1-17.

Bshary, R., Wickler, W., Fricke, H., 2002. Fish cognition: a primate's eye view. Anim. Cogn. 5, 1-13.

Bshary, R., 2011. Machiavellian Intelligence in fishes. In: Brown, C., Laland, K. Krause, J. (Eds.), Fish Cognition and Behavior., 2nd edition. Blackwell Publishing, Ltd., UK, pp. 277-297.

Byrne, R.W., Whiten, A., 1988. Machiavellian Intelligence: Social Expertise and the Evolution of Intellect in Monkeys, Apes, and Humans. Oxford Science Publications, USA, pp. 413.

Chaby, L.E., Sheriff, M.J., Hirrlinger, A.M., Braithwaite, V.A., 2015. Does early stress prepare individuals for stressful future? Stress during adolescence improves foraging under threat. Anim. Behav., 37-45, http://dx.doi.org/10.1016/j. anbehav.2015.03.028.

Coss, R.G., Globus, A., 1978. Spine stems on tectal interneurons in jewel fish are shortened by social stimulation. Science 200, 787-790.

Dukas, R., 2004. Evolutionary biology of animal cognition. Annu. Rev. Ecol. Evol. Syst. 35, 347-374

Dunbar, R.I.M., 1998. The social brain hypothesis. Evol. Anthropol. 6, 178-190.

Dunbar, R.I.M., Shultz, S., 2007. Evolution in the social brain. Science 317, 1344-1347

Dunlap, K.D., Castellano, J.F., Prendaj, E., 2006. Social interaction and cortisol treatment increase cell addition and radial glia fiber density in the diencephalic periventricular zone of adult electric fish, Apteronotus leptorhynchus. Horm. Behav. 50, 10-17.

Ebbesson, L.O.E., Braithwaite, V.A., 2012. Environmental effects on fish neura plasticity and cognition. J. Fish Biol. 81, 2151-2174.

Earley, R.L., Edwards, J.T., Aseem, O., Felton, K., Blumer, L.S., Karom, M., Grober, M.S., 2006. Social interactions tune aggression and stress responsiveness in a territorial cichlid fish (Archocentrus nigrofasciatus). Physiol. Behav. 88, 353-363.

Fernald, R.D., 2009. Social regulation of reproduction: what changes and why? Horm. Brain Behav. 1, 683-691.

Figler, M.H., Einhorn, D.M., 1983. The territorial prior residence effect in convict cichlids (Cichlasoma nigrofasciatum Günther): temporal aspects of establishment and retention, and proximate mechanisms. Behaviour 85 , 157-183.

Galhardo, L., Oliveira, R.F., 2014. The effects of social isolation on steroid hormone levels are modulated by previous social status and context in a cichlid fish. Horm. Behav, 65, 1-5.

Gonçalves-de-Freitas, E., Mariguela, T.C., 2006. Social isolation and aggressiveness in the Amazonian juvenile fish Astronotus ocellatus. Braz. J. Biol. 66, 233-238.

Gonçalves-de-Freitas, E., Teresa, F.B., Gomes, F.S., Giaquinto, P.C., 2008. Effect of water renewal on dominance hierarchy of juvenile Nile tilapia. Appl. Anim. Behav. Sci. 112, 187-195.

Gómez-Laplaza, L.M., Morgan, E., 1991. Effects of short-term isolation on the locomotor-activity of the angelfish (Pterophyllum scalare). J. Comp. Psychol. $105,366-375$

Gómez-Laplaza, L.M., Morgan, E., 2000. Laboratory studies of the effects of short-term isolation on aggressive behaviour in fish. Mar. Freshw. Behav. Phys. 33, 63-102.

Gómez-Laplaza, L.M., Morgan, E., 2003. The influence of social rank in the angelfish, Pterophyllum scalare, on locomotor and feeding activities in a novel environment. Lab. Anim. 37, 108-120.

Han, X., Wang, W., Xue, X., Shao, F., Li, N., 2011. Brief social isolation in early adolescence affects reversal learning and forebrain BDNF expression in adult rats. Brain Res. Bull. 86, 173-178.

Hannes, R.P., Franck, D., 1983. The effect of social-isolation on androgen and corticosteroid levels in a cichlid fish (Haplochromis burtoni) and in swordtails (Xiphophorus helleri). Horm. Behav. 17, 292-301.

Hofmann, C.M., O’Quin, K.E., Marshall, N.J., Cronin, T.W., Seehausen, O., Carleton, K.L., 2009. The eyes have it: regulatory and structural changes both underlie cichlid visual pigment diversity. PLoS Biol. 7 (12), e1000266.

Holder, J.L., Barlow, G.W., Francis, R.C., 1991. Differences in aggressiveness in the Midas cichlid fish (Cichlasoma citrinellum) in relation to sex, reproductive state and the individual. Ethology 88, 297-306.

Howe, K., Clark, M.D., Torroja, C.F., Torrance, J., et al., 2013. The zebrafish reference genome sequence and its relationship to the human genome. Nature 496, 498-503.

Huffman, L.S., Mitchell, M.M., O’Connell, L.A., Hofmann, H.A., 2012. Rising StARs: behavioral, hormonal, and molecular responses to social challenge and opportunity. Horm. Behav. 61, 631-641.

Huntingford, F.A., 2003. Foreword. Fish Fish. 4, 197-198.

Huntingford, F.A., Adams, C., Braithwaite, V.A., Kadri, S., Pottinger, T.G., Sandøe, P., Turnbull, J.F., 2006. Current issues in fish welfare. J. Fish Biol. 68, 332-372.

Kandel, E.R., 2001. Neuroscience - the molecular biology of memory storage: a dialogue between genes and synapses. Science 294, 1030-1038.

Maia, C.M., Volpato, G.L., 2013. Environmental light color affects the stress response of Nile tilapia. Zoology 116, 64-66. 
McNamara, J.M., Green, R.F., Olsson, O., 2006. Bayes' theorem and its applications in animal behaviour. Oikos 112, 243-251.

Manassa, R.P., McCormick, M.I., Chivers, D.P., 2013. Socially acquired predator recognition in complex ecosystems. Behav. Ecol. Sociobiol. 67, 1033-1040.

Nieuwenhuys, R., Meek, J., 1990. The telencephalon of actinopterygian fishes. Cereb. Cortex 8A, 31-73.

Odling-Smee, L., Braithwaite, V.A., 2003a. The role of learning in fish orientation. Fish Fish. 4, 235-246.

Odling-Smee, L., Braithwaite, V.A., 2003b. The influence of habitat stability on landmark use during spatial learning in the threespined stickleback. Anim. Behav. 65, 701-707.

Oliveira, R.F., Almada, V.C., 1996. On the (in)stability of dominance hierarchies in the cichlid fish Oreochromis mossambicus. Aggress. Behav. 22, 37-45.

Øverli, Ø., Pottinger, T.G., Carrick, T.R., Øverli, E., Winberg, S., 2002. Differences in behaviour between rainbow trout selected for high- and low-stress responsiveness. J. Exp. Biol. 205, 391-395.

Panula, P., Chen, Y.-C., Priyadarshini, M., Kudo, H., Semenova, S., Sundvik, M., Sallinen, V., 2010. The comparative neuroanatomy and neurochemistry of zebrafish CNS systems of relevance to human neuropsychiatric diseases. Neurobiol. Dis. 40, 46-57.

Pinho-Neto, C.F., Miyai, C.A., Sanches, F.H.C., Giaquinto, P.C., Delicio, H.C., Barcellos, L.J.G., Volpato, G.L., Barreto, R.E., 2014. Does sex influence intraspecific aggression and dominance in Nile tilapia juveniles? Behav. Process. 105, 15-18.

Portavella, M., Torres, B., Salas, C., 2004. Avoidance response in goldfish: emotional and temporal involvement of medial and lateral telencephalic pallium. J. Neurosci. 24, 2335-2342.

Ramallo, M.R., Morandini, L., Alonso, F., Birba, A., Tubert, C., Fiszbein, A., Pandolfi, M., 2014. The endocrine regulation of cichlids social and reproductive behavior through the eyes of the chanchita, Cichlasoma dimerus (Percomorpha; Cichlidae). J. Physiol. Paris 108, 194-202.

Rodríguez, F., Duran, E., Vargas, J.P., Torres, B., Salas, C., 1994. Performance of goldfish trained in allocentric and egocentric maze procedures suggests the presence of a cognitive mapping system in fishes. Anim. Learn. Behav. 22 , 409-420.

Sabbah, S., Laria, R.L., Gray, S.M., Hawryshyn, C.W., 2010. Functional diversity in the color vision of cichlid fishes. BMC Biol. 8, 133-149.

Salas, C., Broglio, C., Rodriguez, F., 2003. Evolution of forebrain and spatial cognition in vertebrates: conservation across diversity. Brain Behav. Evol. 62, 72-82.

Salvanes, A.G.V., Moberg, O., Ebbesson, L.O.E., Nilsen, T.O., Jensen, K.H., Braithwaite, V.A., 2013. Environmental enrichment promotes neural plasticity and cognitive ability in fish. Proc. R. Soc. B 280, 20131331.

Seehausen, O., 2006. African cichlid fish: a model system in adaptive radiation research. Proc. R. Soc. B 273, 1987-1998.

Shumway, C.A., 2010. The evolution of complex brains and behaviors in African cichlid fishes. Curr. Zool. 56, 144-156.

Sørensen, C., Bohlin, L.C., Øverli, Ø., Nilsson, G.E., 2011. Cortisol reduces cell proliferation in the telencephalon of rainbow trout (Oncorhynchus mykiss). Physiol. Behav. 102, 518-523.

Teresa, F.B., Gonçalves-de-Freitas, E., 2011. Reproductive behavior and parental roles of the cichlid fish Laetacara araguaiae. Neotrop. Ichthyol. 9, 355-362.

Volpato, G.L., Barreto, R.E., 2001. Environmental blue light prevents stress in the fish Nile tilapia. Braz. J. Med. Biol. Res. 34, 1041-1045.

von Krogh, K., Sørensen, C., Nilsson, G.E., Øverli, Ø., 2010. Forebrain cell proliferation, behavior, and physiology of zebrafish, Danio rerio, kept in enriched or barren environments. Physiol. Behav. 101, 32-39.

Young, D., Lawlor, P.A., Leone, P., Dragunow, M., During, M.J., 1999. Environmental enrichment inhibits spontaneous apoptosis, prevents seizures and is neuroprotective. Nat. Med. 5, 448-453.

Zhang, L., Zhou, R.L., Li, X.X., Ursano, R.J., Li, H., 2006. Stress-induced change of mitochondria membrane potential regulated by genomic and non-genomic GR signaling: a possible mechanism for hippocampus atrophy in PTSD. Med. Hypotheses 66, 1205-1208.

Zupanc, G.K.H., 2008. Adult neurogenesis and neuronal regeneration in the brain of teleost fish. J. Physiol. Paris 102, 357-373. 